九州大学学術情報リポジトリ

Kyushu University Institutional Repository

\title{
THE ANT GENUS CERAPACHYS F. SMITH OF JAPAN, WITH DESCRIPTION OF A NEW SPECIES (HYMENOPTERA, FORMICIDAE)
}

Ogata, Kazuo

https://doi.org/10.5109/2441

出版情報: ESAKIA. 20，pp.131-137，1983-12-15. Entomological Laboratory，Faculty of Agriculture, Kyushu University バージョン：

権利関係 : 


\title{
THE ANT GENUS CERAPACHYS F. SMITH OF JAPAN, WITH DESCRIPTION OF A NEW SPECIES (HYMENOPTERA, FORMICIDAE)*
}

\author{
Kazuo Ogata \\ Entomological Laboratory, Faculty of Agriculture, \\ Kyushu University, Fukuoka 81’2, Japan
}

\begin{abstract}
Two species of the ant genus Cerapachys of Japan are treated; one of which, C. humicola, is described and illustrated as new based on the worker, the ergatoid queen and the male. The distribution of Japanese Cerapachys is mapped.
\end{abstract}

The genus Cerapachys was established by F. Smith in 1875 based on a single type species C. antennatus F. Smith from Sarawak. This genus is characteristic of the robust antenna1 scape, the box-like trunk, the large first gastric segment (abdominal IV), the presence of the tibia1 spur of middle leg and the denticulate margination of the pygidium. Brown (1975) listed 137 world species of the genus in his revision. The genus Cerapachys belongs to the subfamily Cerapachyinae, which is sometimes placed as a tribe within the subfamily Ponerinae by some authors (Brown, 1975 et al.).

In Japan, the genus has been represented by only a single species C. biroi Fore1 from the Ryukyus (Wilson \& Taylor, 1967). In this paper another species, C. humicola, is described and illustrated as new from the southern area of Japan. Additionally, notes on the distribution of Japanese Cerapachys are given.

Measurements, indices and their abbreviations follow Brown's definitions (Brown, 1975).

Before going further I wish to express my sincere thanks to Prof. Y. Hirashima and Assoc. Prof. K. Morimoto, Entomological Laboratory, Kyushu University, Fukuoka, for their constant guidance. I am very grateful to Dr. M. Kubota, Odawara, Mr. K. Masuko, Tokyo Metropolitan University, Tokyo, Mr. H. Sakai, Ashigara and Mr. M. Terayama, Utsunomiya University, Utsunomiya, for their kindness in offering valuable materials. My thanks are also due to Dr. R. Sonobe, Imaichi, for his useful information.

* Contribution from the Entomological Laboratory, Faculty of Agriculture, Kyushu University, Fukuoka (Ser. 3, No. 136). 


\section{Cerapachys humicola n. sp.}

(Figs. 1-13)

Worker: HW 0.44-o. $48 \mathrm{~mm}$, HL 0.52-0. $62 \mathrm{~mm}$, CI 73-85, SL 0.92-o. $31 \mathrm{~mm}, \mathrm{ML}$ 0.24-o. $26 \mathrm{~mm}$, WL 0.74-o. $82 \mathrm{~mm}$, petiolar node L 0.25-o. $30 \mathrm{~mm}$, petiolar node W 0.25-o. $30 \mathrm{~mm}$, postpetiolar node L 0.35-o. $44 \mathrm{~mm}$, postpetiolar node W 0.35-o. 45 $\mathrm{mm}$, TL 2.79-3.10 $\mathrm{mm}$.

Head rectangular, subparallel-sided ; posterior margin slightly concave in full face view; posterior corner forming right angle. Occipital carina distinct, surrounding occipital foramen squarely. Eye absent. Frontal area with raised carinae in the middle contiguously; lateral corner with small process anteriorly. Clypeus depressed ; anterior margin straight. Antenna 11-segmented; antenna1 scape clavate, short, as long as 7 following segments together; second segment small, received in hollow of scape; apical segment large, bulbous, as long as 5 preceding segments together. Mandible subtriangular, with edentate masticatory border and acute apex. Palp formula of maxillary 2-, labial 2-segmented.

Trunk rigid, parallel-sided; dorsal surface flat, without suture ;pronotum anteriorly rounded in dorsal view, without margination; propodeum truncate posteriorly, with weakly marginate declivity. Metasternal process distinct.

Petiolar and postpetiolar nodes as broad as long. Petiolar node parallelsided, narrower than trunk; subpetiolar process triangular. Postpetiolar node trapezoidal, broadest at posterior border which is broader than trunk. First gastric segment large, about $1.5 \mathrm{x}$ as long as postpetiolar node.

Legs short; middle leg with pectinate tibia1 spur, as in fore and hind legs.

Body surface opaque, with fine reticulation. Hairs short, pale yellow, suberect or decumbent. Color reddish brown.

Ergatoid queen : HW 0.48-o. $50 \mathrm{~mm}$, HL 0.56-o. $66 \mathrm{~mm}$, CI 76-86, SL 0.30-o. 31 mm, ML 0.25-o. $31 \mathrm{~mm}$, WL 0.80-o. $92 \mathrm{~mm}$, petiolar node L 0.29-o. $31 \mathrm{~mm}$, petiolar node W 0.30-o. $33 \mathrm{~mm}$, postpetiolar node L 0.43-0. $50 \mathrm{~mm}$, postpetiolar node W 0.44-o. $50 \mathrm{~mm}$, TL 3.13-3.53 mm.

Body form and proportions like those of worker, but slightly larger in size.

Eyes present but variable, with one pigmented spot to about 35 facets (diameter $0.13 \mathrm{~mm}$ ). Anteromedian ocellus present or absent; if present, situated in the $1 / 5$ of $\mathrm{HL}$ from posterior margin of head. Paired posterior ocelli absent in specimens examined.

Sculpture, pilosity and coloration as in worker.

Male : HW 0.56-o. $60 \mathrm{~mm}$, HL 0.50-o. $60 \mathrm{~mm}$, CI 100-112, SL 0.19-o. $20 \mathrm{~mm}, \mathrm{ML}$ 0. 18-O. $21 \mathrm{~mm}$, WL 0.96-1. $00 \mathrm{~mm}$, petiolar node L $0.24-0.25 \mathrm{~mm}$, petiolar node W 0.23-o. $25 \mathrm{~mm}$, postpetiolar node L 0.29-o. $31 \mathrm{~mm}$, postpetiolar node W 0.31-o. 34 $\mathrm{mm}$, TL 1.80-1. $90 \mathrm{~mm}$, fore wing L 2.06-2.16 mm. 


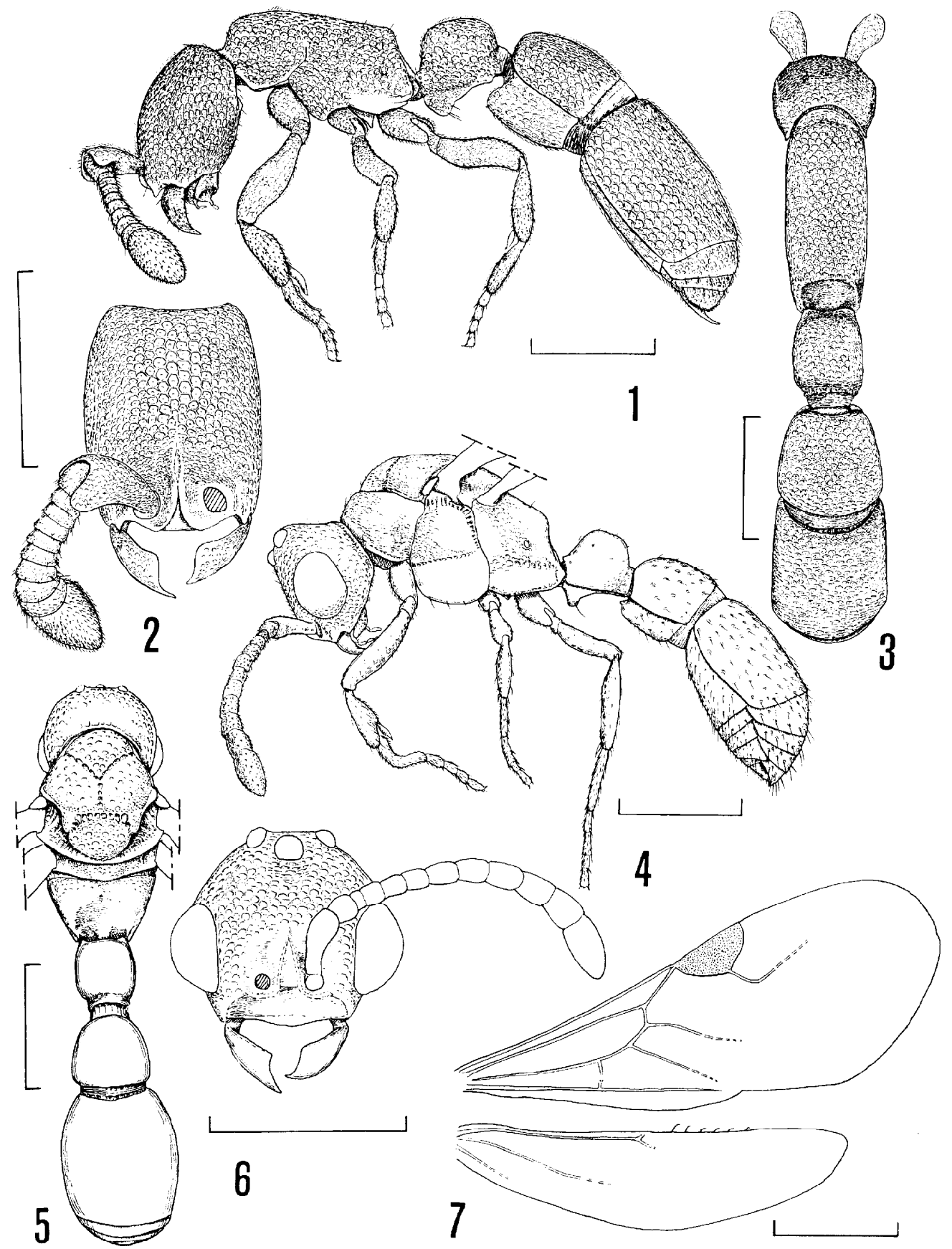

Figs. 1-7. Cerapachys humicola n. sp. 1, Worker, lateral view; 2, worker, head, full face view; 3, worker, dorsal view; 4, male, lateral view; 5, male, dorsal view; 6, male, head, full face view; 7, male, right fore and hind wings. Scale: $0.5 \mathrm{~mm}$. 

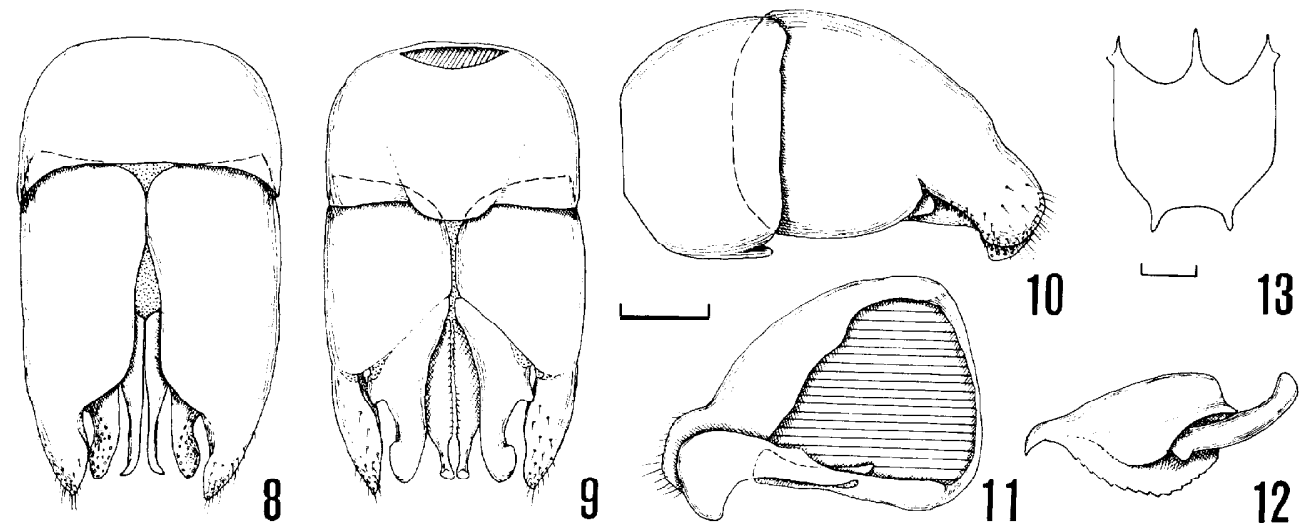

Figs. 8-13. Male genitalia and subgenital plate of Cerapachyshumicola n. sp. 8, Genital capsule, dorsal view ;9, same, ventral view; 10, same, left lateral view; 11, left paramere and volsella, inner lateral view; 12, right aedeagal plate, lateral view; 13, subgenital plate, ventral view. Scale: $0.1 \mathrm{~mm}$.

Head, excluding eyes, slightly narrower than trunk; vertex depressed, forming flat area. Occipital carina distinct as in worker. Eye large, about $0.24 \mathrm{~mm}$ in greatest diameter. Frontal area as in worker, but carinae less raised and separated more widely; anterolateral corner without process. Clypeus broad; anterior margin rounded. Antenna 12-segmented;scape thick, short, as long as 3 following segments together; third antennal segment smallest, $1 / 2$ as long as fourth segment; apical segment large, longer than 2 preceding segments together. Mandible developed, subtriangular, as in worker. Palp formula of maxillary 4-, labial 2-segmented.

Trunk rigid ; mesoscutum with distinct notauli ; propodeal declivity slightly concave, without margination.

Petiole and postpetiole like those of worker, but with more rounded corners. First gastric segment large, $1.5 \times$ as long as postpetiolar node.

Fore wing with reduced veins; $r-m$ and $m-c u$ cross veins absent; stigma large and distinct.

Legs long; tibial spurs of fore, middle and hind legs as in worker.

Subgenital plate with two distinct projections apically. Genitalia retractile; basal ring broader than long, somewhat heavily screlotized ventrally ; paramere rounded apically in lateral view, ventral surface concave at apical $1 / 3$ of its length; volsella with large digitus and small cuspis; digitus with sensillae on outer surface; both partly visible through ventral concavity of paramere in lateral view. Aedeagal plate subtriangular; apex acute, directed downward and curved outside.

Body surface with small punctures, which are abundant on head, scutum and scutellum; interspaces smooth and shining. Pilosity as in worker, but sparser. Body black, legs and antenna lighter. 
ноготуре : Worker (Type No. 2425, Kyushu Univ.), Mt. Shiratake, Tsushima, Nagasaki Pref., Kyushu, 13. vi. 1979 (K. Ogata), (Colony No. CE-0002).

Paratypes: [Honshu] 1 ergatoid queen, 1 worker, Mt. Kiyosumi, Chiba Pref., 1976 (T. Kannari) ; 3 ergatoid queen, 2 workers, Manazuru, Kanagawa Pref., 23. vi. 1968 (M. Kubota) ; 2 males, Manazuru, Kanagawa Pref., 14. vii. 1981 (K. Masuko) ; 5 males, 10 workers, Manazuru, Kanagawa Pref., 16. viii. 1981 (H. Sakai) ; 1 worker, Kino, Kyoto, 2. x. 1956 (S. Uéno); 1 worker, Takarazuka, Hyogo Pref., 15. vi. 1974 (M. Tanaka). [Kyushu] 2 ergatoid queens, 3 workers, same data as holotype (from the same nest as holotype) ; 1 ergatoid queen, 6 workers, Mt. Shiratake, Tsushima, Nagasaki Pref., 14. vii. 1981 (K. Ogata), (Colony No. CE-0003) ; 1 ergatoid queen, Minamata, Kumamoto Pref., 1. iv. 1970 (M. Kubota) .

REMARKs: Colony No. CE-0002 and CE-0003 nested in the soil. All the materials were collected from the floor of the evergreen broadleafed forests.

Brown (1975) divided the world Cerapachys into 18 informal species-groups, and this species belongs to his fragosus-group which is characteristic of the

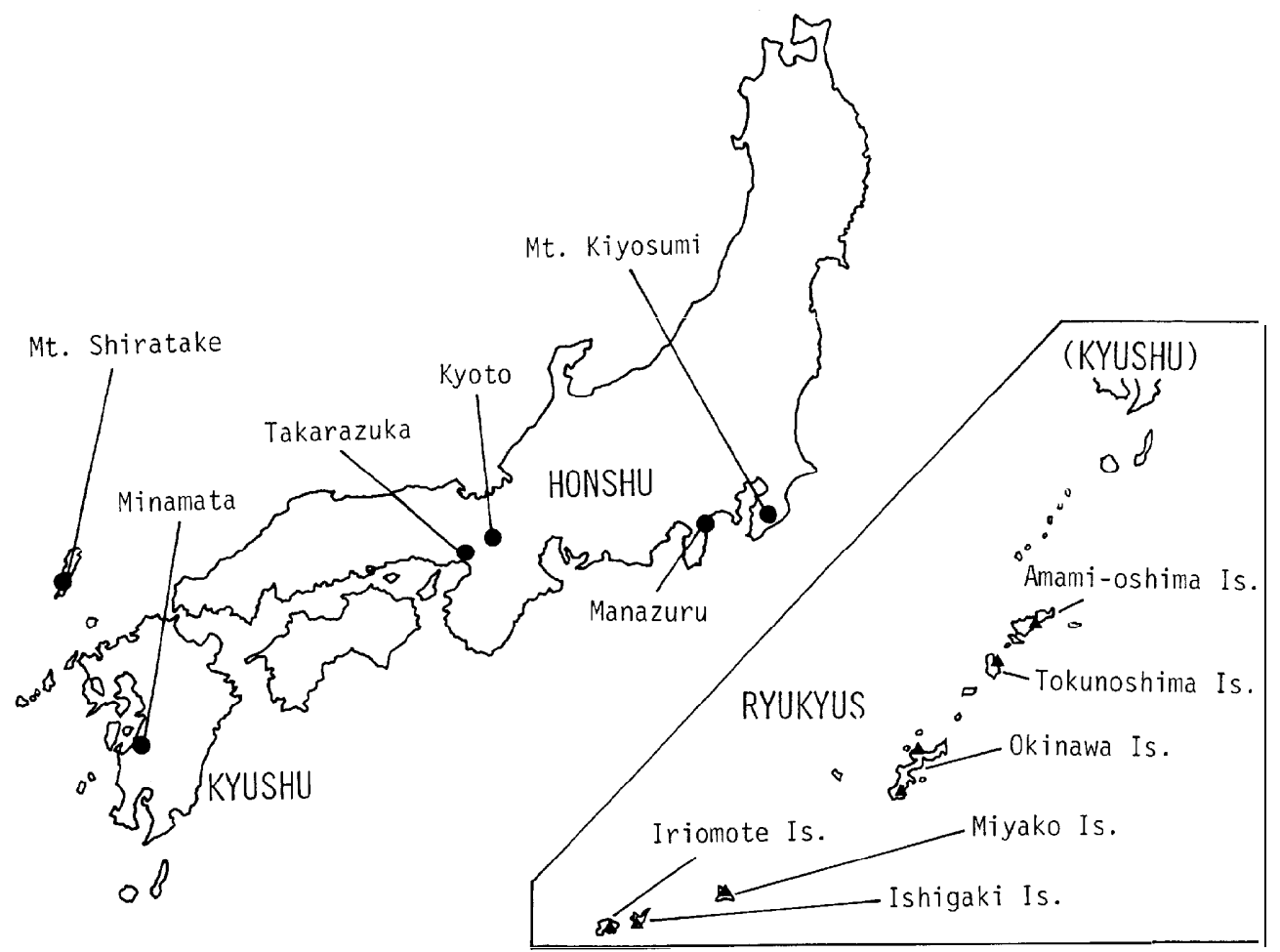

Fig. 14. Distributions of Japanese Cerapachys species. Circle: C. humicola n. sp. Triangle : C. biroi Forel. 
small-sized body, the reduction or absence of eyes in the worker, the small petiole and postpetiole in relation to large first gastric segment, crowded punctures and the 11-segmented (sometimes lo-segmented) antenna. Among the fragosus-group, which consists of fragosus (Roger), coecus (Mayr) and besucheti Brown, this species most resembles fragosus from Ceylon, in having the slender body (with $\mathrm{HW}<\mathrm{O}$. 50mm) and complete lacking of eye in the worker. But it is distinguished from C. fragosus by the shape of the petiolar and postpetiolar nodes, each of which is as broad as long.

The male of humicola is unique in having the E-segmented antenna and distinct notauli. So far as I know, the antenna is 13-segmented and the notauli is absent for the male of Cerapachys.

The distribution is mapped in Fig. 14.

\section{Cerapachys biroi Fore1}

Cerapachys biroi Forel, 1907, Ann. Mus. Nat. Hung., 5: 7 (Singapore) ; Brown, 1975, Search, 5: 22.

Cerapachys silvestrii Wheeler, 1909, Bol. Lab. Zool. Gen. Agr. Portici, 3: 269 (Hawaii: Hilo). Syscia silvestrii: Wilson \& Taylor, 1967, Pac. Ins. Mon., 14: 94.

Cerapachys sinensis Wheeler, 1928, Bol. Lab, Zool. Gen. Agr. Portici, 24: 3 (China: Shanghai).

Cerapachys seini Mann, 1931, J. Wash. Acad. Sci., 21 : 440 (Puerto Rico: Rio Piedras).

Cerapachys ierensis Weber, 1939, Ann. Ent. Soc. Amer., 32 : 94 (Trinidad: St. Augustine).

Syscia typhla Roger: Sonobe, 1973, Sesoko Mar. Sci. Lab. Tech. Rep., (2) : 15. [Misidentification.]

SPecimens examined: [Ryukyus) 3 workers, Tokunoshima Is., 19. iii. 1980 (M. Terayama) ; 80 workers, Chinen, Okinawa Is., 25. iv. 1979 (K. Ogata); 3 workers, Miyako Is., 20. viii. 1979 (M. Terayama) ; 2 workers, Mt. Banna, Ishigaki Is., 28. iv. 1979 (K. Ogata).

Distribution : Widely spread through Orient, from Nepal, India and China to South East Asia, and also introduced to Pacific Islands and West Indies. In Japan, this species is restricted to the Ryukyus (Fig. 14). The first record of this species from Japan was made by Wilson \& Taylor (1967) under the name of Syscia silvestrii which was synonymized by Brown (1975). Up to present Amami-Oshima Island is the northern limit of the distribution (Abe, 1977; Terayama, 1981).

REMARKS: This species is easily distinguished from C. humicola by the following characters : Antenna with 9 segments; pronotum marginate anteriorly; subpetiolar process constricted basally; body surface with numerous small punctures, interspaces smooth and shining.

Onoyama (1976) pointed out that a record of Syscia typhla from Okinawa (Sonobe 1973) is doubtful. Dr. Sonobe kindly informed me of his misidentification. 


\section{References}

Abe, T. 1977. A preliminary study on the ant fauna of the Tokara Islands and Amamioshima. Ecol. Stud. Nat. Cons. Ryukyu Isl., 3: 93-102.

Brown, W. L. Jr. 1975. Contribution toward a reclassification of the Formicidae. V. Ponerinae, tribes Platythyreini, Cerapachyini, Cylindromyrmecini, Acanthostichini and Aenictogitini. Search, $5: 1-115$.

Onoyama, K. 1976. A preliminary study on the ant fauna of Okinawa-Ken, with taxonomic notes (Japan ; Hymenoptera : Formicidae). Ecol. Stud. Nat. Cons. Ryukyu Isl., 2: 121141.

Terayama, M. 1981. Distribution of ants of the Nansei Archipelago. (I) Ants in the Amami Islands. Nature and Insects, 16(8):34-36. (In Japanese)

Wilson, E. 0. and R. W. Taylor 1967. The ants of Polynesia (Hymenoptera : Formicidae). Pac. Ins. Mon., 14: 1-109. 